\title{
Albinapis gracilis gen.n. e sp.n. e Hexantheda enneomera sp.n. do Sul do Brasil (Hymenoptera, Colletidae, Paracolletini) ${ }^{1}$
}

\author{
Danúncia Urban ${ }^{2}$ \\ Vinalto Graf ${ }^{2}$
}

\begin{abstract}
Albinapis gracilis gen.n. and sp.n. and Hexantheda enneomera sp.n. from Southern Brazil (Hymenoptera, Colletidae, Paracolletini). Albinapis gracilis gen.n. and sp.n. from Caçapava do Sul and Hexantheda enneomera sp.n. from Capão da Canoa, Rio Grande do Sul, Brazil, with peculiar number of labial palpi articles, are described and illustrated.

KEY WORDS. Hymenoptera, Colletidae, Albinapis, Hexantheda, taxonomy
\end{abstract}

São descritos dois Paracolletini com palpos labiais peculiares, Albinapis gracilis gen.n. e sp.n. com cinco artículos e Hexantheda enneomera sp.n. com nove artículos. Este gênero era conhecido anteriormente só pela espécie-tipo. MICHENER (1989) redescreveu Hexantheda Ogloblin, 1948, como sub-gênero de Leioproctus Smith, 1853, e comentou a ocorrência de seis ou sete artículos nos palpos labiais de H. missionica Ogloblin, 1948. No entanto, outras estruturas além do número de artículos dos palpos labiais separam nitidamente $H$. enneomera sp.n. da espécie-tipo.

O material tipo está depositado na Coleção de Entomologia Pe. J.S. Moure, Departamento de Zoologia, Universidade Federal do Paraná (DZUP). As medidas são em milímetros

\section{Albinapis gen.n.}

Figs $1-5,13,16,17$

Espécie-tipo: Albinapis gracilis sp.n.

Tegumento preto e brilhante. Olhos quase paralelos; labro estreito; clípeo pouco protuberante, de perfil, tão largo como a gena (fig. 2); área supraclipeal brilhante e convexa (Fig. 1); vértice expandido atrás dos olhos; distância ocelo-occipital, em vista frontal, quase igual ao diâmetro do ocelo $(0,16: 0,18)$; mandíbulas com dente pré-apical; palpos labiais com cinco artículos, tão longos como a metade do premento, somente o artículo distal ultrapassando a glossa (Fig. 3); lobos da glossa fracamente arredondados, pêlos distais formando franja quase reta; antenas com escapo longo, alcançando a tangente inferior do ocelo mediano, maior que a metade do flagelo $(0,54$ : $0,84)$; flagelômeros muito curtos, tão longos como um terço da sua largura, exceto o primeiro e o distal mais longos que largos; asas anteriores com duas células sub-mar-

1) Contribuição número 1168 do Departamento de Zoologia, Universidade Federal do Paraná.

2) Departamento de Zoologia, Universidade Federal do Paraná. Caixa Postal 19020 , 81531-990 Curitiba, Paraná, Brasil. Bolsista do CNPq. 

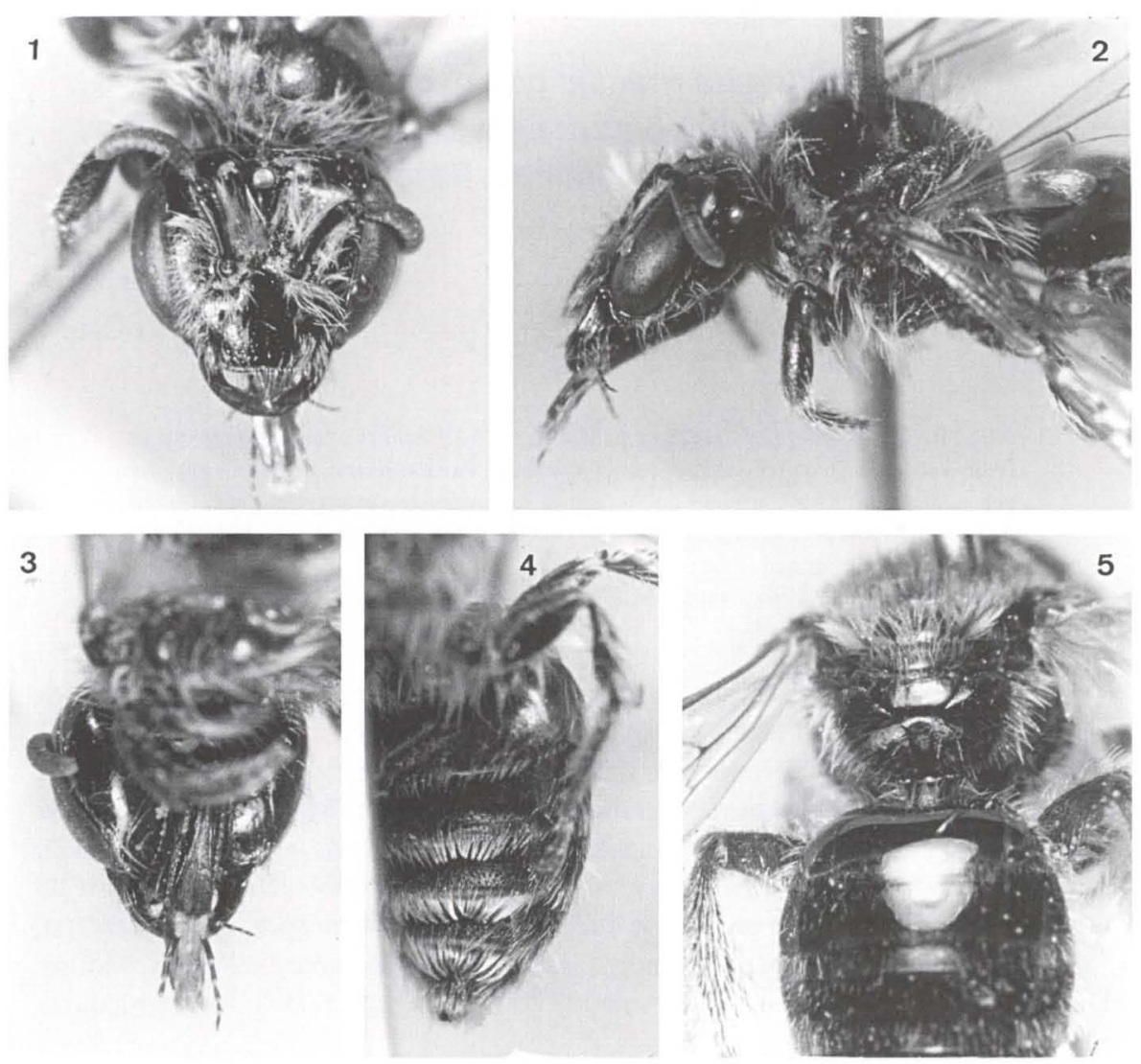

Figs 1-5. Albinapis gracilis, holótipo macho (1-4), alótipo (5). (1) Cabeça em vista frontal; (2) cabeça e mesosoma em perfil; (3) cabeça em vista posterior; (4) esternos; (5) parte do mesosoma e tergos basais.

ginais; tíbias posteriores sem carena ao longo do comprimento; esporões tibiais posteriores quase iguais em comprimento; propódeo com área basal sub-horizontal plana e alongada, mais longa que o metanoto (Fig. 5), separada da área posterior por angulosidade fraca; sulcos espiraculares largos e rasos aos lados da área basal e muito finos em direção ao ápice do propódeo.

Macho. Mandíbulas com a margem superior convexa; sétimo esterno com as placas laterais e as medianas arredondadas, recobertas com pêlos curtos e finos, as medianas maiores e com pêlos finos na margem (Fig. 16); oitavo esterno com o processo distal tão longo como o restante do esclerito (Fig. 13); face ventral dos gonocoxitos com o contorno interno sem emarginação, ápice do gonóstilo arredondado (Fig. 17).

Fêmea. Mandíbulas com a margem superior quase reta; metade basal do terceiro ao quinto esterno quase glabra, micro-reticulada e sem pontos grandes, escopa densa e com pêlos curtos na metade apical. 
Etimologia. Nome em homenagem ao Prof. Dr. Albino Morimasa Sakakibara do Departamento de Zoologia, Universidade Federal do PAraná.

Comentário. Albinapis pertence aos Paracolletini com duas células sub-marginais nas asas anteriores, lobos da glossa curtos e com franja distal quase reta $\mathrm{e}$ mandíbulas do macho com dente pré-apical. Na chave de MICHENER (1989) poderia entrar em uma modificação do item 17, juntamente com Hexantheda, na primeira parte do dilema, referente à presença de mais de quatro artículos nos palpos labiais. Hexantheda tem os lobos da glossa dispostos em V com o revestimento piloso acompanhando o recorte; OGLOBLIN (1948: 172) descreveu, entretanto, como "glosas cortas y redondeadas"; antenas com os flagelômeros medianos pouco mais curtos que largos; área supraclipeal com triângulo discal achatado; tíbias posteriores com esporão interno distintamente maior que o externo; triângulo propodeal e tergos foscos; triângulo propodeal com base sub-horizontal mais curta que o metanoto. Sétimo esterno do macho com placas laterais bífidas, as medianas curtas e largas (Figs 14, 15); oitavo esterno com projeção distal mais longa que a área basal (Figs 11,12 ); face ventral do gonocoxito com o contorno interno marcado por recorte dentiforme (OGLOBLIN 1948: fig. 23). Fêmea com escopa ventral longa e decumbente, pêlos maiores que duas vêzes o comprimento do distitarso.

\section{Albinapis gracilis sp.n.}

Holótipo macho. Tegumento preto, exceto: antenas, a partir do terceiro flagelômero, amarelo-acastanhadas por baixo, em forma de mancha pequena no terceiro e aumentando gradativamente o amarelo-acastanhado nos seguintes; pterostigma castanho-amarelado; tergos e esternos castanhos com margem translúcida larga.

Pilosidade branca, face ventral dos basitarsos branco-creme. Pêlos longos na cabeça e mesosoma; esparsos e decumbentes no clípeo (Figs 1,2); na fronte mais longos que três diâmetros do ocelo; face vertical e lados do tergo basal com pêlos esparsos, o restante quase glabro (Fig. 5); muito curtos, decumbentes e esparsos do segundo ao quinto tergo, porém na margem e nos lados um pouco mais longos, sem formar franjas; tergos distais mais denso-pilosos.Terceiro ao quinto esterno com pêlos decumbentes no disco e franja sedosa apical, nos lados a franja mais longa e voltada para o meio (Fig. 4).

Clípeo brilhante com pontuação esparsa e fina, distância entre os pontos maior que dois diâmetros de ponto; paroculares com área lisa e brilhante junto aos olhos ocupando um terço da sua largura; vértice liso e brilhante entre os ocelos e os olhos (Fig. 1); propódeo brilhante e com micro-reticulação na área basal (Fig. 5), restante liso, brilhante e quase sem pontos na face dorsal, lateralmente com densa micro-pontuação; tergos brilhantes, os dois basais quase desprovidos de pontos, do terceiro ao quinto com pontos muito finos e esparsos, mais densos junto à base.

Comprimento aproximado 6,50; largura da cabeça 2,20; comprimento do olho 1,34; comprimento da asa a partir do esclerito costal 4,75.

Alótipo fêmea. Tegumento e caracteres estruturais como no macho. Pilosidade amarelo-esbranquiçada na cabeça, lobos pronotais e dorso do mesosoma; branca nos mesepisternos e pernas; levemente amarelada no ápice das tíbias e nos 

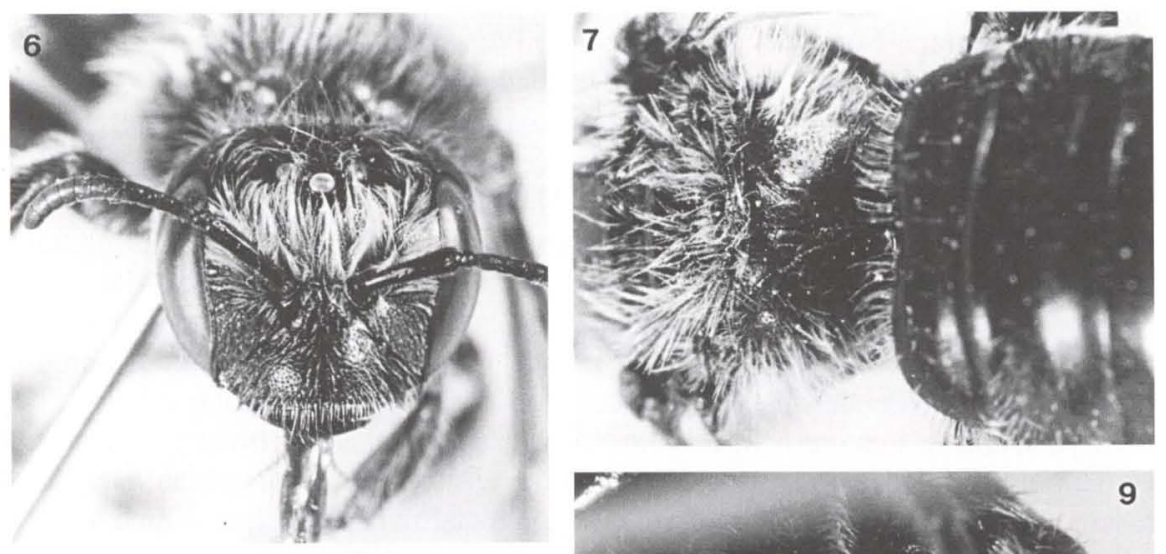

8
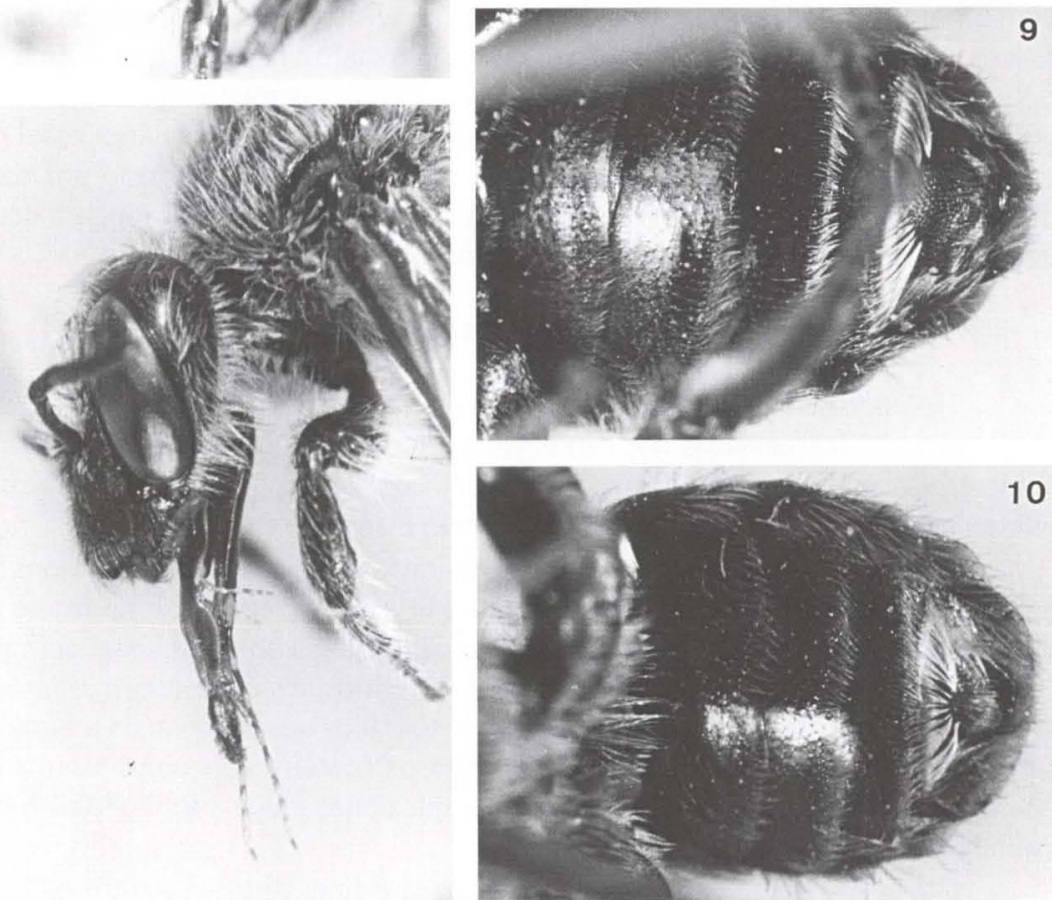

Figs 6-10. Hexantheda enneomera, holótipo macho $(6,8,9)$, parátipo macho (7), Hexantheda missionica (10). (6) Cabeça em vista frontal; (7) parte do mesosoma e tergos basais; (8) cabeça e parte do mesosoma em vista lateral; $(9$ e 10) esternos.

basitarsos anteriores, com área acastanhada subapical nas tíbias medianas; tíbias posteriores amarelo-esbranquiçadas, com estria castanho-pálida da placa basitibial até o ápice; nos tergos basais como no macho, quinto e sexto tergos com pilosidade densa, branco-creme.

Comprimento aproximado 6,42; largura da cabeça 2,20; comprimento do olho 1,36; comprimento da asa a partir do esclerito costal 4,92.

Distribuição geográfica. BRASIL, Rio Grande do Sul. 
Holótipo macho. Brasıl, Rio Grande do Sul: Caçapava do Sul, Guaritas, 10.X.1991, C. Schlindwein leg. Alótipo e parátipos com os mesmos dados de procedência, o alótipo coletado em 13.X.1991; três parátipos fêmeas em 26.V.1991 e uma fêmea em 9.X.1991 (DZUP).

Etimologia. Nome alusivo ao aspecto gracioso dos exemplares.

\section{Hexantheda enneomera sp.n.}

Figs $6-9,11,14$

Holótipo macho. Tegumento preto, tergos e esternos com margem translúcida estreita branco-amarelada, exceto os distais inteiramente pretos; asas fracamente tingidas com castanho para o ápice, pterostigma marrom-claro.

Pilosidade branca, na face ventral dos basitarsos amarelo-pálida. Na cabeça, os pêlos tão longos como dois a três diâmetros do ocelo, exceto os do clípeo e paroculares inferiores, no clípeo mais curtos que metade do diâmetro do ocelo; no mesosoma e dois tergos basais longa e esparsa, pêlos mais curtos no ápice do segundo tergo, formando franjas laterais; nos demais tergos curtos e semi-eretos, decumbentes na margem, o terceiro com franjas laterais, no quarto e quinto tergos com franja completa; pêlos mais longos nos dois distais; esternos com pêlos curtos e esparsos, eretos do primeiro ao quinto; no terceiro e quarto com franjas apicais curtas, os pêlos voltados para o meio; no quinto esterno a franja apical sedosa e densa, os pêlos laterais muito longos e também voltados para o meio, os medianos mais curtos formando um arco, mais largo que em $H$. missionica (Figs 9, 10).

Palpos labiais com nove artículos, medindo o dobro do comprimento da glossa e um pouco mais longos que o premento (Fig. 8); clípeo pontuado com áreas lisas esparsas (Fig. 6); área supraclipeal com elevação triangular plana; escapo quase a metade do comprimento do flagelo $(0,96 \times 1,60)$, alcançando o ocelo mediano; tíbia posterior com projeção apical tuberculada, em forma de anel, junto ao esporão interno; propódeo e tergos micro-reticulados e quase foscos, propódeo lineolado na área basal (Fig. 7) e tergos com pontos esparsos muito finos.

Comprimento aproximado 10,67; largura da cabeça 3,28; comprimento do olho 2,04; comprimento da asa excluindo o esclerito costal 7,92.

Alótipo fêmea. Tegumento e caracteres estruturais como no macho. Pilosidade branca predominando, exceto cerdas amarelo-acastanhadas no labro e na depressão sub-marginal do clípeo; pernas anteriores com pêlos amarelados na ponta da tíbia e amarelo-acastanhados no basitarso, cerdas ventrais do basitarso castanhas; pernas medianas e posteriores com pêlos marrom-escuros em quase todo o lado externo da tíbia e o lado externo do basitarso, cerdas ventrais dos basitarsos amarelo-acastanhadas; nos dois tergos distais a pilosidade marrom-escura.

Comprimento aproximado 9,83; largura da cabeça 3,04; comprimento do olho 1,92; comprimento da asa, excluindo o esclerito costal 7,50.

Distribuição geográfica. BRASIL, Rio Grande do Sul.

Holótipo macho. BRASIL, Rio Grande do Sul: Capão da Canoa, Arroio Teixeira, 19.IX.1992, I. Alves dos Santos leg.. Mesmos dados e mesmo coletor: 

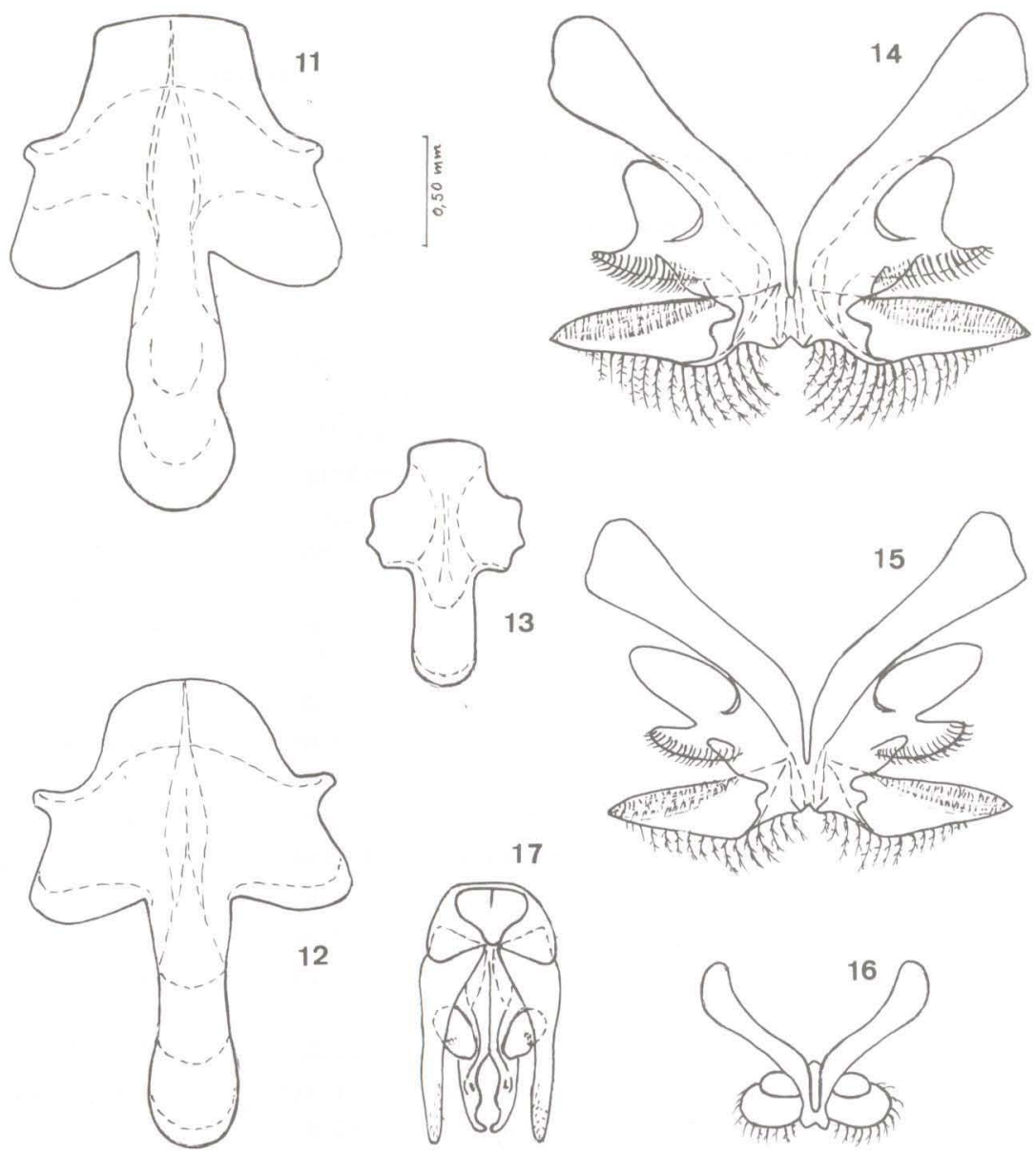

13

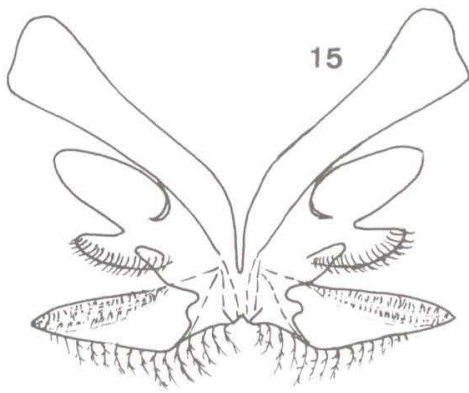

17
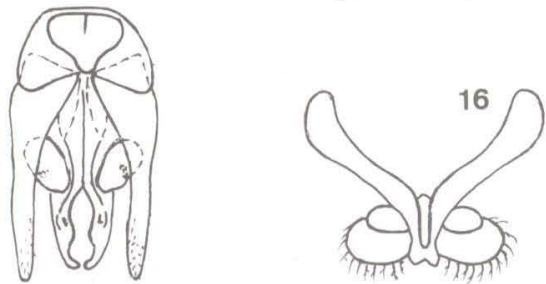

Figs 11-17. Hexantheda enneomera $(11,14)$, Hexantheda missionica (12, 15), Albinapis gracilis $(13,16,17)$. $(11,12,13)$ Oitavo esterno; $(14,15,16)$ sétimo esterno; $(17)$ genitália. Escala $=0,50 \mathrm{~mm}$.

alótipo fêmea coletado em 18.X.1992 e os parátipos: 16.XI.1991 uma fêmea e um macho, 18.X.1992 uma fêmea. Demais parátipos do Rio Grande do Sul: Osório, 13.XI.1991, I. Alves dos Santos leg. um macho; Guaíba, BR 116 km 307, 13.X.1990, C. Schlindwein leg. um macho; mesmo local e coletor, 3.XI.1990 um macho e duas fêmeas (DZUP).

Etimologia. Do grego "enneos" = nove + "meros" = artículos.

Comentários. Hexantheda missionica difere de $H$. enneomera pelos palpos labiais com seis artículos, tão longos como dois terços do premento; o escapo pouco menor que o flagelo $(1,20: 1,40)$ ultrapassando o ocelo lateral; macho com pilosi- 
dade marginal densa e alongada no clípeo, tíbia posterior sem projeção apical tuberculada junto ao esporão interno. H. missionica ocorre na ARGENTINA, Formosa e Misiones e no Brasil, Paraná e Rio Grande do Sul (Canela).

\section{REFERÊNCIAS BIBLIOGRÁFICAS}

Ogloblin, A. 1948. Descripción de dos géneros nuevos de Paracolletini Argentinos (Colletidae, Apoidea, Hymenoptera). Notas Mus. La Plata, Zool., 13 (106): 165-178.

MichenER, C.D. 1989. Classification of American Colletinae (Hymenoptera, Apoidea). Univ. Kansas Sci. Bull. 53 (11): 622-703.

Recebido em 26.VIII.1999; aceito em 14.VIII.2000. 